\title{
Letter to the Editor: "Comparison of efficacy of kinesiological taping and subacromial injection therapy in subacromial impingement syndrome"
}

\author{
Gökçe Leblebici $^{1}$ • Derya Çelik ${ }^{2}$
}

Received: 28 September 2015 / Accepted: 18 October 2015 / Published online: 26 October 2015

(C) International League of Associations for Rheumatology (ILAR) 2015

To the Editors,

With great interest, I have read the article of Subașı and colleagues [1] Comparison of efficacy of kinesiological taping and subacromial injection therapy in subacromial impingement syndrome. The authors presented result of kinesiological taping versus subacromial injection in patients with subacromial impingement syndrome. While I value the reported clinical data, I am concerned by the unclear result section and inconsistencies between the abstract and the manuscript.

My initiate concern is that data presented in tables. The authors did not give any subheading which demographic data belongs to which group in Table 1 . Bold values which is 0.000 should have been given 0.001 in Table 2 . In addition, the authors did not give any information of what the bold values mean in Tables 2 and 3. The authors stated that the Student's $t$ test and Mann-Whitney $U$ test were used for data analysis in the method section. However, tables did not include any information which statistical method belongs to which table.

Next, the authors presented the significant difference in terms of flexion degree in favor of injection group $(p=$ $0.004)$ in the abstract. However, it was reported that the significant difference between the groups was only found in active extension in Table $3(p=0.004)$. In addition, the assessment of extension and adduction is not usual and also not essential to follow-up in patients with subacromial impingement syndrome. Mostly, the clinicians aim to decrease pain between 90-120 degree of elevation which is painful arch and pain in internal rotation. Therefore, improvement of extension and adduction range of motion do not improve the symptoms of the patients.

Finally, the combination of the unclear presentation of the tables and inconsistent result of significant value presented in that study can lead the reader to inaccurate conclusion of the study.

Sincerely,

Compliance with ethical standards

Disclosures None.

\section{Reference}

1. Subașı V, Çakır T, Arıca Z, Sarıer RN, Bilgilisoy FM, Koldaș DŞ, Toraman NF (2014) Comparison of efficacy of kinesiological taping and subacromial injection therapy in subacromial impingement syndrome. Clin Rheumatol. doi:10.1007/s10067-014-2824-7, published online Nov 18, 2014

Gökçe Leblebici

leblebicigokce@gmail.com

1 Istanbul University, Institute of Health Sciences, Department of Physiotherapy and Rehabilitation, Istanbul, Turkey

2 Faculty of Health Sciences, Division of Physiotherapy and Rehabilitation, Istanbul University, 34740 Bakırkoy, Istanbul, Turkey 